\title{
O Programa Milton Santos de Acesso ao Ensino Superior - PROMISAES: uma política pública educacional para a promoção da democracia social
}

\section{The Programa Milton Santos de Acesso ao Ensino Superior - PROMISAES: a public policy education for the promotion of social democracy}

\author{
Carmo, R.J. do ${ }^{1}$ \\ ${ }^{1}$ Universidade do Estado de Minas Gerais, João Monlevade, MG, Brasil. \\ renatacarmog@gmail.com
}

\begin{abstract}
RESUMO
Este artigo aborda a perspectiva de democracia racial no Brasil através da análise de uma política pública educacional: o Programa Milton Santos de Acesso ao Ensino Superior - PROMISAES. Para sua elaboração, utilizou-se o edital de seleção de novembro de 2010, os pedidos deferidos e indeferidos, os cursos escolhidos pelos estudantes do PEC-G - Programa de Estudantes-Convênio de Graduação, a origem desses alunos e as universidades escolhidas por eles. Além de analisar os dados coletados pelo edital de seleção, este trabalho também faz uma reflexão sobre a importância das políticas públicas educacionais para a promoção da democracia social, a qual vai muito além da democracia racial proposta por Gilberto Freyre.
\end{abstract}

Palavras-chave: PROMISAES, Política pública educacional, Democracia racial.

\begin{abstract}
This article approaches the perspective of racial democracy in Brazil through an analysis of public education policy: the Programa Milton Santos de Acesso ao Ensino Superior - PROMISAES. For its elaboration, we used the selection announcement of selection of November 2010 that reports the accepted and rejected applications, the courses chosen by students of Programa de Estudantes - Convênio de Graduação - PEC$\mathrm{G}$, the origin these students and the universities chosen by them. Besides analyzing the data collected by the announcement of selection, this work also reflects on the importance of public educational policies for the promotion of social democracy, which goes beyond racial democracy proposed by Gilberto Freyre.
\end{abstract}

Keywords: PROMISAES, Public education policy, Racial democracy. 


\section{INTRODUÇÃO}

Falar de políticas públicas, de uma forma mais geral, significa observar as estruturas de poder e de dominação presentes nos conflitos contidos no tecido social.

Dessa forma, tratar das políticas públicas educacionais significa considerar que elas se articulam num projeto de sociedade que se propõe implantar ou que já está em curso.

Azevedo (2004, p. 57) destaca que "abordar a educação como política social requer diluí-la na sua inserção mais ampla: o espaço teórico-analítico próprio das políticas públicas, que representam a materialidade da intervenção do Estado, ou o Estado em ação."

Nessa perspectiva está inserido o Programa Milton Santos de Acesso ao Ensino Superior - PROMISAES, que tem por objetivo fomentar a cooperação técnico-científica e cultural entre os países com os quais o Brasil mantém acordos - em especial os africanos - nas áreas de educação e cultura, consolidando uma política de intercâmbio que busca promover uma maior integração entre o Brasil e outros países em desenvolvimento.

Partindo do exposto, este trabalho procura descrever o Programa Milton Santos de Acesso ao Ensino Superior e os estudantes de graduação africanos atendidos por ele, tendo como base o processo de seleção de novembro de 2010. Conjuntamente, traçam-se as características socioeconômicas desses estudantes, assim como se discute sobre a importância desse programa para a promoção da democracia social.

Para a construção deste artigo, foram utilizados alguns questionamentos que serviram de parâmetro de análise do processo de seleção do Programa Milton Santos de novembro de 2010, sendo eles:

- Qual o número de candidatos inscritos e selecionados no processo?

- Quais os critérios que servem de base para este processo de seleção?

- Quais as nacionalidades dos estudantes africanos inscritos e selecionados?

- Quais são os cursos mais e menos contemplados por este programa?

No levantamento bibliográfico, foram utilizadas informações qualitativas e quantitativas expostas pelo portal do Ministério da Educação - MEC, assim como entrevistas semiestruturadas e questionários com os envolvidos no programa. $\mathrm{Na}$ sequência, essas informações foram confrontadas com o conceito de democracia racial, refletido, porém não elaborado, por Gilberto Freyre. 
Na visão de Freyre, o conceito de democracia racial se tornou um mito por aceitar a ausência de preconceito e de discriminação racial no Brasil, como também se tornou uma ideologia ao produzir um senso de alívio entre os brancos, os quais se viram eximidos de qualquer responsabilidade para com os problemas raciais no país.

O estudo aqui proposto foi pautado na hipótese da carência de caracterização socioeconômica dos estudantes africanos de graduação ingressos no PROMISAES em 2010, fato este que consequentemente dificulta o monitoramento e a avaliação do programa, como também a promoção da democracia social.

Nessa perspectiva, este trabalho poderá ser utilizado como referência para a implantação, o monitoramento e a avaliação do programa nas universidades, o que, consequentemente, promoverá uma maior interação do governo brasileiro para com os países conveniados, reafirmando e incrementando suas relações diplomáticas, econômicas e políticas.

\section{METODOLOGIA}

Para a construção deste material, foi feito um levantamento de leituras relacionadas com os conceitos de democracia social e racial, bem como a identificação das Instituições Federais de Ensino Superior - IFES envolvidas com o PROMISAES no Brasil; quais os estudantes beneficiados por este programa; as origens desse público; e quais as instituições brasileiras de ensino superior com maior número de beneficiados. Nesse processo, buscaram-se dados numéricos sobre os estudantes que solicitaram esse benefício; quais trabalhos discutiam sobre as políticas de ação afirmativa nas Instituições de Ensino Superior; quais eram as universidades participantes dessa seleção; quais os cursos mais procurados e os motivos da escolha desses estudantes.

Em seguida, ao se perceber que não seria possível realizar o trabalho envolvendo todas as instituições, optou-se por delimitar o perfil do programa a partir de dados e entrevistas com estudantes africanos ingressos na Universidade Federal de Viçosa - UFV pelo PEC-G.

Para a construção das entrevistas e seleção dos entrevistados, foram identificados os estudantes participantes do programa na UFV, suas características, como tiveram conhecimento do PROMISAES e, tendo como base essas informações, foram construídos os questionários e as entrevistas. Essas entrevistas foram estruturadas a partir de 
levantamento bibliográfico com o intuito de confrontá-las com as fontes bibliográficas nas perspectivas de democracia social e democracia racial. Esse material de sondagem foi utilizado com 7 estudantes oriundos de Angola, Guiné Bissau, Moçambique e Senegal.

Essa etapa serviu para a continuidade e conclusão do proposto, uma vez que, com as informações e dados coletados, conclusões importantes foram levantadas, como, por exemplo, os desejos e ambições desse grupo de estudantes, a visão que eles possuem das instituições de ensino brasileiras, como também foi possível conhecer um pouco a realidade de ensino dos seus países de origem.

\section{RESULTADOS E DISCUSSÃO}

Incentivar a promoção de políticas públicas voltadas aos descendentes de seres humanos que foram escravizados significa mitigar e, de certa forma, reconhecer a importância deles para a construção e o desenvolvimento de muitos países do mundo ocidental. Nesse sentido, os acordos de cooperação técnico-científica, acadêmica, cultural e tecnológica das instituições de ensino brasileiras e do Estado brasileiro com os países africanos devem se orientar no contexto da globalização, objetivando estreitamento das relações políticas e econômicas de cooperação na luta contra a pobreza, a desigualdade e a exclusão social.

Fonseca (2009) analisa o processo migratório do africano para o Brasil, a partir dessas políticas, em três tempos: (i) as políticas de cooperação institucional para a educação superior de graduação e pós-graduação; (ii) os acordos de cooperação técnica, científica, social e cultural de transferência e intercâmbio em áreas diversas; (iii) a migração estudantil e os fluxos estimulados pelos Acordos de Cooperação.

Na perspectiva de Ferreira (2008), a ideologia de democracia racial serve de base para a ideia de que, uma vez abolida a escravidão, os/as negros/as adquiriram cidadania imediata, numa imagem de harmonia ou paraíso racial local, onde muitos indivíduos de raças diferentes conviveriam sem qualquer tipo de problema ou conflito.

Segundo Heilbom, Araújo e Barreto (2010d, p.5)

O Brasil, com "s" é um país imerso num tipo de racismo específico, o "racismo cordial”, cuja manifestação se dá em espaços privados, mas que tem impacto no público e na (re) produção de desigualdade ${ }^{1}$ entre negros/as e brancos/as.

\footnotetext{
${ }^{1}$ Ação injustificada de diferenciação de acesso e fruição de bens, serviços e oportunidades, nas esferas pública e privada, em virtude de raça, cor, descendência ou origem nacional ou étnica. Ver Estatuto da Igualdade Racial-Lei no $12.288 / 2010$.
} 
Explicar a lógica do racismo brasileiro com bases estritamente de classes é uma discussão, ao menos no campo sociológico, datada, com dias contados.

Um dos pensadores dessa ideia de democracia racial foi Gilberto Freyre que, apesar de não cunhar o conceito, transmitiu em suas obras uma visão positiva da mistura racial elogiando a mestiçagem brasileira e a tolerância em relação a ela. Dessa forma, "A positivação da mistura de raças serviu como fator de união de um país gigante e heterogêneo, e também como instrumento de repressão às manifestações 'culturais' que se mostrassem alheias ao projeto" (JUNIOR, 2004, p.8). Como consequência disso, o preconceito se tornou um tabu, pois o que se transmitiu foi que ele não poderia existir em um país cujo cerne de sua identidade é a dissolução do conceito de raça através da miscigenação.

Na perspectiva de Heilbom, Araújo e Barreto (2010a), vários pesquisadores como, por exemplo, Florestan Fernandes (1965) tentam interpretar a ideia de democracia racial como um mito, ou seja, uma ideologia que mascararia as verdadeiras relações sociais permeadas pela dominação dos brancos/as em relação aos negros/as. O autor Guimarães (s/d) apud Heilbom, Araújo e Barreto (2010b, p. 2) relata que a democracia racial deve ser entendida a partir das mudanças que o conceito sofre nas fases de sua elaboração, apropriação e (re)elaboração por parte dos indivíduos em conjunturas históricas distintas. Ele destaca que haveria três momentos de democracia racial: o ideal, o pacto e o mito. $\mathrm{O}$ ideal constitui o momento de elaboração do conceito que via o Brasil como um exemplo de paraíso racial. O segundo momento, o pacto, se dá quando a democracia racial serve como alicerce para a coalizão de grupos políticos, sociais e raciais distintos que visam implementar, de fato, a democracia racial. Por fim, a última fase, que corresponde ao mito, faz referências ao momento em que essa aliança é quebrada e a ideia de democracia racial passa a ser vista como falácia.

O conceito de democracia social, na visão de Dias (2006), preconiza a preservação da igualdade política e a transformação da desigualdade social existente nas instituições públicas e privadas através de mecanismos participativos.

\subsection{O Programa Milton Santos de Acesso ao Ensino Superior - PROMISAES}

O Programa Milton Santos de Acesso ao Ensino Superior é uma homenagem ao intelectual, pesquisador, político, jornalista, geógrafo e professor Milton Santos. Sua 
trajetória política e intelectual reafirmou sua luta por justiça e igualdade através da participação de homens e mulheres negros (as) na construção do país.

Ao longo de sua vida, Milton Santos escreveu 40 livros, foi coautor de dezenas de outros e publicou artigos, foi articulista e editor em jornais brasileiros importantes, como Folha de São Paulo, Correio Braziliense e o jornal A Tarde, da Bahia e, na década de 90, ganhou prêmios como o Estação Cultural e o Vautrin Lud (considerado o Nobel da Geografia). Graças a sua luta e dedicação ao entendimento das estruturas formativas das desigualdades entre os homens e as sociedades humanas ao redor do mundo seu trabalho serviu de inspiração para o que hoje veio a se constituir como o Fórum Social Mundial. Devido à grande importância desse escritor negro e baiano para a geografia e principalmente para a sociedade, o Programa de Acesso ao Ensino Superior tem o seu nome na sua intitulação.

De acordo com a portaria ${ }^{\circ} 3.167$, de 13 de setembro de 2005, o PROMISAES consiste na oferta de auxílio financeiro para alunos estrangeiros, participantes do PEC-G, regularmente matriculados em cursos de graduação das Instituições Federais de Ensino Superior - IFES. Para concorrer ao PROMISAES, o estudante, além de estar matriculado em Instituição Federal de Ensino Superior vinculada ao PEC-G, deve ter um bom desempenho acadêmico, seguindo as exigências da universidade em que estuda, tendo como limite o tempo máximo de permanência no curso estabelecido pela IFES a que o estudante estiver vinculado.

Conforme informado pelo Ministério da Educação e Cultura, o Programa de Estudantes -Convênio de Graduação - PEC-G é uma atividade de cooperação, cujo objetivo é a formação de recursos humanos, a fim de possibilitar aos cidadãos de países em desenvolvimento, com os quais o Brasil mantém acordos educacionais ou culturais, realizarem estudos universitários no país, em nível de graduação nas Instituições de Ensino Superior (IES) brasileiras participantes do PEC-G.

O programa envolve estrangeiros, entre 18 e 25 anos de idade, com ensino médio completo, preferencialmente os que estejam inseridos em programas nacionais de desenvolvimento socioeconômico, acordados entre o Brasil e os países conveniados por via diplomática. Tais programas definem o compromisso do aluno de regressar ao seu país e contribuir com a área na qual se graduou. Para se inscrever, os interessados devem procurar as missões diplomáticas brasileiras ou repartições consulares em data definida pelo Ministério das Relações Exteriores. 
De acordo com o Ministério da Educação, o processo de seleção ocorre em duas etapas, sendo uma delas feita pelas missões diplomáticas brasileiras que encaminham a relação dos candidatos para a Divisão de Formação e Treinamento do DCT/MRE e a Divisão de Assuntos Internacionais da SESu/MEC. No ato da inscrição, é necessário que o candidato apresente os seguintes documentos: declaração de compromisso, histórico escolar do ensino médio, comprovante de capacidade econômica dos pais e responsáveis, acompanhado da declaração de conclusão. Todos eles, com exceção do primeiro, devem conter a devida autenticação do Consulado Brasileiro. Também é necessária a aprovação no Exame de Proficiência em Língua Portuguesa para Estrangeiros - CELPE-Bras para os candidatos não-lusófonos. Os candidatos dos países onde ainda não se aplica o CELPEBras, bem como os que fizeram o exame e não obtiveram aprovação, deverão ser submetidos a um novo exame CELPE-Bras ao final do curso de português para estrangeiros no Brasil, durante o primeiro semestre, como condição para o ingresso no curso acadêmico pretendido, apenas no segundo semestre.

A seleção final é feita em Brasília por meio da Divisão de Formação e Treinamento do DCT/MRE e a Divisão de Assuntos Internacionais da SESu/MEC, assessorados por uma comissão indicada pelo Fórum de Pró-Reitores de Graduação das Universidades Brasileiras, sendo que os resultados são divulgados pelas missões ou pelas representações diplomáticas.

Compete a essa comissão a distribuição das vagas oferecidas pelas IES entre os candidatos dos países participantes, sendo que não existe reserva de vagas ou quotas específicas para cada país, sendo o critério da seleção o mérito acadêmico.

No Gráfico 1 pode ser verificada a desigualdade na distribuição das instituições de Ensino Superior participantes do PEC-G em todo o país, com destaque para as regiões Sul e Sudeste. Ao se analisar esses dados, pode-se destacar um fator que influencia nesta observação - o contingente populacional dessas regiões. É fato que as maiores populações do país se encontram na porção Sul-Sudeste do Brasil, porém, a análise não ficará presa somente a estes dados, buscando ir além do trivial. É necessário destacar o privilégio do Estado em desenvolver atividades de ensino-pesquisa nessas áreas do país. 
Gráfico 1 - Quantidade de Instituições participantes do PEC-G por regiões brasileira

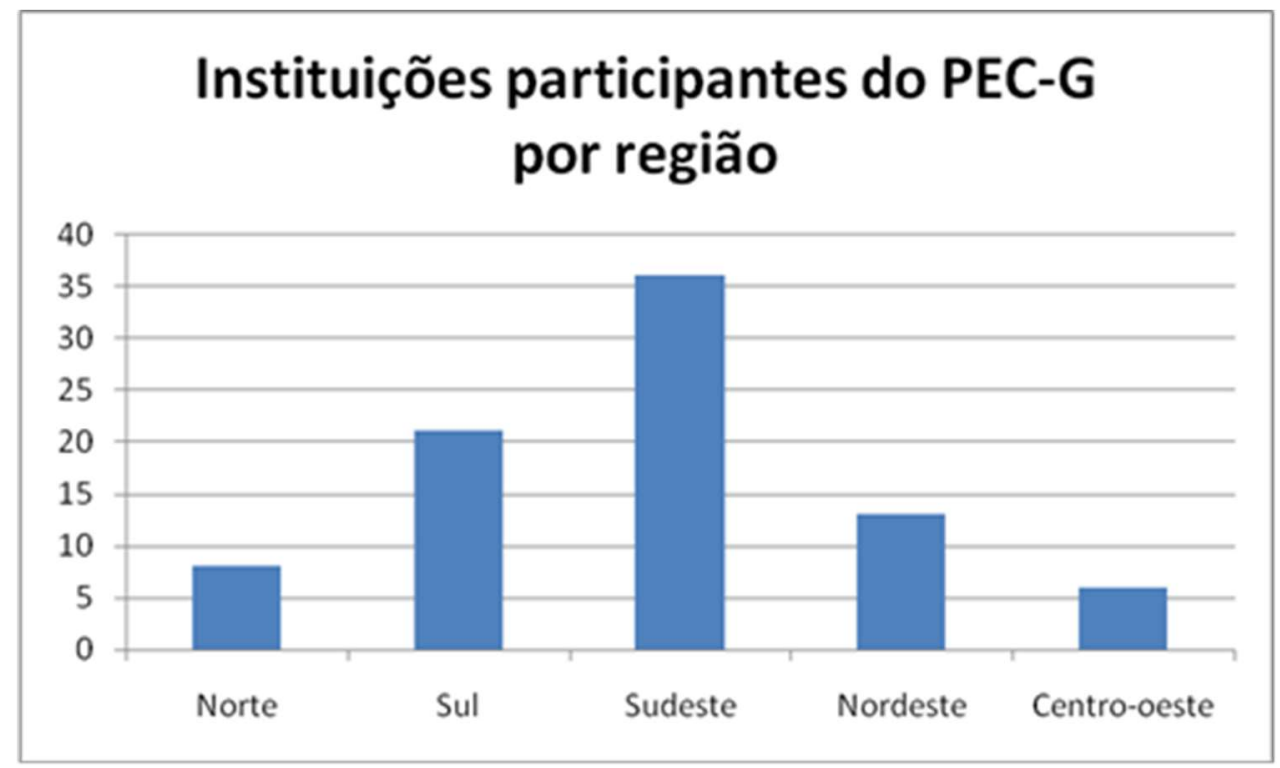

Fonte: Ministério da Educação, 2011.

Tomando como ponto de análise o Quadro 1, nota-se que apenas 19 dos 54 países pertencentes ao continente africano fazem parte do Programa de Estudantes - Convênio de Graduação - PEC-G, ou seja, uma minoria de países do continente pode participar do PROMISAES. Dessa forma identifica-se que somente alguns dos estudantes africanos podem solicitar o benefício nas Instituições de Ensino Superior do Brasil, fato este que limita consideravelmente as ações dessa política afirmativa no referido continente.

Quadro 1 - Países africanos pertencentes do Programa de Estudantes- Convênio de Graduação- PEC-G

\begin{tabular}{||l|l||}
\hline 1 & África do Sul \\
\hline 2 & Angola \\
\hline 3 & Benin \\
\hline 4 & Cabo Verde \\
\hline 5 & Camarões \\
\hline 6 & Costa do Marfim \\
\hline 7 & Gabão \\
\hline 8 & Gana \\
\hline 9 & Guiné-Bissau \\
\hline \hline 10 & Máli \\
\hline \hline 11 & Moçambique \\
\hline 12 & Namíbia \\
\hline 13 & Nigéria \\
\hline
\end{tabular}




\begin{tabular}{||l|l||}
\hline 14 & Quênia \\
\hline 15 & República do Congo \\
\hline \hline 16 & República Democrática do Congo \\
\hline \hline 17 & São Tomé \& Príncipe \\
\hline 18 & Senegal \\
\hline 19 & Togo \\
\hline \hline
\end{tabular}

Fonte: Ministério da Educação, 2011.

O Gráfico 2 representa a relação de IFES brasileiras classificadas regionalmente e que trabalham com o PROMISAES. Tendo em vista os dados gerados, percebe-se que a região que possui maior número de Instituições de Ensino Superior que trabalham com o PROMISAES é a região Nordeste, que oferta o benefício em $84,6 \%$ de suas instituições. Já a região Sul é a que representa a menor quantidade de Instituições de Ensino Superior que trabalham com o programa. $\mathrm{Na}$ análise desses dados, observa-se que há uma má distribuição entre a quantidade de instituições de ensino superior no país e o quantitativo de instituições participantes do programa. A região Sudeste possui a maior quantidade de IFES, porém não possui proporcionalmente o mesmo destaque na participação do programa. Já a região Nordeste, que está em terceiro lugar no quantitativo de IFES, possui o maior número de instituições que adotam o PROMISAES.

Gráfico 2 - Representação em porcentagem de IFES brasileiras que trabalham com o PROMISAES, distribuição regional

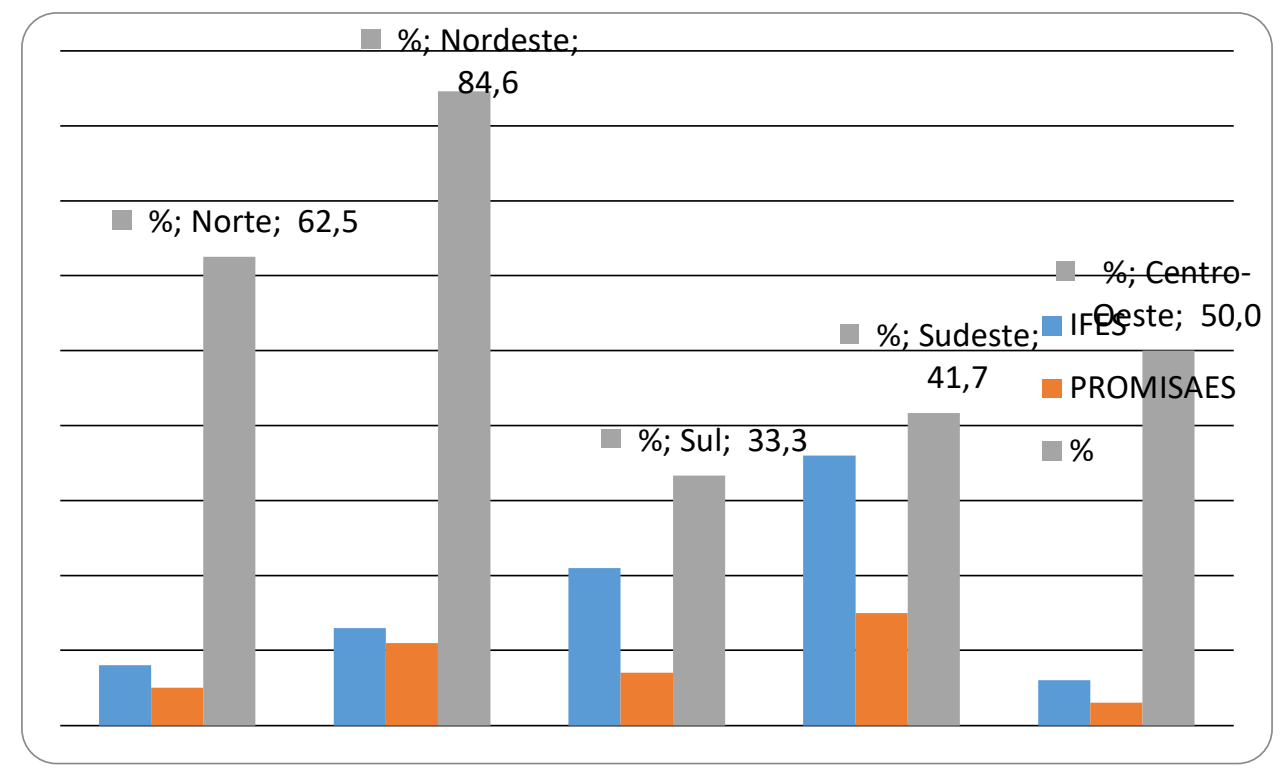

Fonte: Ministério da Educação, 2011.

Tendo como base o edital de novembro de 2010, é possível apontar alguns dados levantados de que se inferem algumas informações muito pertinentes ao estudo. Pode-se 
perceber, de acordo com o número de inscrições, que foram solicitados, no referido edital, 472 pedidos, sendo que destes, 436 são de origem africana, e dos quais foram indeferidas apenas 46 inscrições. Interpreta-se que em 2010 a porcentagem de estudantes contemplados esteve em torno de $90 \%$, uma taxa bastante alta em relação ao número de solicitações. (Quadro 2)

Em relação aos pedidos indeferidos, faz-se necessário mencionar que solicitaram a participação no programa pessoas de países conveniados com o Brasil, ou seja, países não necessariamente africanos. Logo, no cálculo de inscrições indeferidas, acrescentamse 5 inscrições de pessoas latino-americanas. (Quadro 3)

Quadro 2 - Porcentagem de pedidos deferidos por país africanos em novembro 2010

\begin{tabular}{|l|l|l||}
\hline País & Quantidade & \% \\
\hline Angola & 26 & 6,0 \\
\hline Benim & 6 & 1,4 \\
\hline Cabo Verde & 133 & 30,5 \\
\hline Camarões & 1 & 0,2 \\
\hline Costa do Marfim & 1 & 0,2 \\
\hline Gana & 3 & 0,7 \\
\hline Guiné Bissau & 200 & 45,9 \\
\hline Moçambique & 4 & 0,9 \\
\hline Nigéria & 5 & 1,1 \\
\hline Quênia & 3 & 0,7 \\
\hline $\begin{array}{l}\text { República Democrática } \\
\text { do Congo }\end{array}$ & 37 & 8,5 \\
\hline São Tomé e Príncipe & 16 & 3,7 \\
\hline Senegal & 1 & 0,2 \\
\hline TOTAL & 436 & 100,0 \\
\hline \hline
\end{tabular}

Fonte: Ministério da Educação, 2011.

Quadro 3 - Porcentagem de pedidos indeferidos por país africanos em novembro 2010

\begin{tabular}{|l||r|r|}
\hline País & Quantidade & \% \\
\hline \hline Angola & 3 & 7,3 \\
\hline Benim & 0 & 0 \\
\hline Cabo Verde & 13 & 31,7 \\
\hline Camarões & 1 & 2,4 \\
\hline Costa do Marfim & 0 & 0 \\
\hline Gana & 0 & 0 \\
\hline
\end{tabular}




\begin{tabular}{|l|r|r|}
\hline Guiné Bissau & 13 & 31,7 \\
\hline Moçambique & 0 & 0 \\
\hline Nigéria & 0 & 0 \\
\hline \hline Quênia & 1 & 2,4 \\
\hline Rep. Dem. Congo & 6 & 14,6 \\
\hline São Tomé & 3 & 7,3 \\
\hline Senegal & 1 & 2,4 \\
\hline Total & 41 & 100 \\
\hline
\end{tabular}

Fonte: Ministério da Educação, 2011.

Existem no Brasil diversas instituições de ensino municipais, estaduais e federais, que promovem algum tipo de ação afirmativa na educação superior, contudo, há variações quanto ao modelo adotado, seja por sistema de cotas, seja por bonificação de pontos, seja por reserva de vagas etc. Há também diversidade em relação ao grupo envolvido, variando entre negros, indígenas, pessoas portadoras de necessidades especiais, alunos da rede pública, mulheres negras etc.

\subsection{O PROMISAES na Universidade Federal de Viçosa - UFV}

Para qualificar a discussão deste trabalho, foram feitas algumas entrevistas com parte dos estudantes beneficiados e com o responsável direto do PROMISAES na Universidade Federal de Viçosa - MG.

De acordo com a entrevista feita em 2010 com o funcionário técnico que trabalha diretamente com o Programa na UFV, vale observar que o PROMISAES é de responsabilidade da Prof ${ }^{a}$. Nilda de Fátima Ferreira Soares, Reitora da UFV, que supervisiona a Diretoria de Relações Internacionais e Interinstitucionais - DRI.

Na UFV o mencionado projeto teve inicio em janeiro de 2006. Esse projeto
contempla o Programa de Estudantes-Convênio de Graduação, por meio de
estudantes que tenham bom aproveitamento escolar e não infrinjam o
protocolo que normatiza e disciplina o programa. A seleção é realizada
semestralmente e podem participar os alunos que atendam às condições do
edital e os selecionados passam a receber, por um ano (janeiro a dezembro ou
julho a junho) o valor de um salário mínimo vigente, desde que mantenhamo
desempenho acadêmico, podendo se inscrever a cada nova seleção.
(Informação verbal)

O entrevistado destacou que o programa possui também a função de melhorar a qualidade de vida dos beneficiários, bem como, consolidar políticas sociais voltadas a 
estudantes estrangeiros de baixa renda, proporcionando dignidade e cidadania. Ele ainda acrescenta que o programa tem por função:

\begin{abstract}
Fomentar a cooperação técnico-cientifica e cultural entre os países com os quais o Brasil mantém acordos nas áreas de Educação e Cultura, consolidando uma política de intercâmbio e de promoção de uma maior integração entre os países em desenvolvimento. (Informação verbal)
\end{abstract}

De acordo com a entrevista, a Universidade Federal de Viçosa possuía 29 (vinte e nove) estudantes estrangeiros do PEC-G, desses, apenas 7 (sete) estavam recebendo o benefício. Quando questionado sobre a baixa relação de estudantes contemplados pelo programa, o entrevistado respondeu que:

A baixa relação de estudantes agraciados se dá pela impossibilidade de vários estudantes não atenderem às exigências do edital, às conclusões de cursos e às suspensões do pagamento por infringirem as determinações do edital. (Informação verbal)

Tendo como referência a resposta do entrevistado, constata-se que a seleção do PROMISAES na UFV se baseia em:

1. Situação consular junto à Polícia Federal, feita de acordo com as informações prestadas pela IFES (eliminatória).

2. Rendimento acadêmico (Índice de Rendimento Acadêmico).

3. Condição socioeconômica, de acordo com as informações prestadas pela IFES.

4. Participação do estudante em atividades acadêmicas informadas no formulário de inscrição.

5. Custo de vida local.

6. Índice de Desenvolvimento Humano - IDH - do país de origem do estudante.

O entrevistado também afirmou que, naquele momento, todos os estudantes contemplados pelo programa eram africanos e que:

A demanda é proporcional à necessidade e interesse desse seguimento. Os cursos mais procurados não são necessariamente os preenchidos. Isso se deve à fragilidade acadêmica de base desses estudantes. Historicamente, grande parte migra para cursos das áreas de Ciências Humanas por não aportarem conhecimentos de base para formação em áreas de maiores exigências, como as Ciências Exatas. (Informação verbal)

Quadro 4 - Número de estudantes contemplados pelo PROMISAES por país, em estudo na UFV em 2010

\begin{tabular}{||l||c||}
\hline \hline País & Total \\
\hline \hline Angola & 01 \\
\hline \hline
\end{tabular}




\begin{tabular}{||l||c||}
\hline \hline Moçambique & 01 \\
\hline Senegal & 01 \\
\hline \hline S. T. e Príncipe & 01 \\
\hline \hline Guiné Bissau & 03 \\
\hline \hline TOTAL & $\mathbf{0 7}$ \\
\hline \hline
\end{tabular}

Fonte: Ministério da Educação, 2011.

Analisando o Quadro 4 que identifica o número de estudantes africanos e suas origens, podemos inferir que a preferência desses estudantes na Universidade Federal de Viçosa ocorre principalmente com os de origem de Guiné-Bissau.

Como complemento deste trabalho, foram feitas entrevistas com alguns estudantes beneficiados pelo programa, as quais objetivaram identificar o conhecimento que esses estudantes possuíam sobre o PROMISAES.

No conjunto de perguntas que se relacionavam ao conhecimento sobre o programa foi percebido que os estudantes possuem pouco ou quase nenhum conhecimento sobre ele. Os estudantes demonstraram desconhecimento dos critérios de seleção dos beneficiados pelas bolsas, da cota de bolsa dividida para cada universidade e seus respectivos cursos, quais os órgãos responsáveis pelo PROMISAES no país (sabem apenas os responsáveis na universidade), como recorrer caso sua solicitação seja indeferida, dentre outras importantes informações. Eles relataram que só sabem que o PROMISAES oferece um benefício financeiro. Em complemento a esta sondagem, foram feitas perguntas sobre a divulgação do programa nos países conveniados. Nos relatos dos entrevistados foi confirmada a deficiência deste programa no que se trata da sua divulgação, tanto no Brasil quanto nos países envolvidos. Este fato dificulta a efetividade e a eficácia do PROMISAES, uma vez que sua abrangência é enorme, porém sua divulgação apresenta-se ineficiente. Alguns estudantes relataram que receberam algumas informações acerca do processo de seleção através de correio eletrônico, mas a maioria afirmou que obteve o conhecimento através de informações de amigos e pesquisa na internet.

Os entrevistados destacaram a importância do programa no que se refere ao auxilio financeiro, pois com essa ajuda eles têm a oportunidade de conhecer e estudar aqui no Brasil, promovendo a interação cultural. Observando esse relato, conclui-se que essa mistura cultural é muito vantajosa também para o país, uma vez que há uma troca de conhecimento e aprendizagem sobre a vida desses estrangeiros. Foi perceptível durante a 
entrevista que os estudantes possuíam curiosidade de conhecer melhor o Brasil, assim como a admiração pelo sistema de ensino desenvolvido no país.

Quanto ao questionamento sobre o valor do benefício e a compatibilidade da vida financeira, as respostas foram unânimes em destacar que o valor não é suficiente para custear totalmente a vida numa cidade universitária. Os estudantes informaram que devido aos atrasos no pagamento e ao valor do benefício ser incompatível com o custo de vida, a ajuda financeira dos familiares é primordial. Eles ainda acrescentaram que a situação dos bolsistas nas capitais brasileiras é pior, uma vez que o custo de vida nessas cidades é ainda mais alto.

A entrevista continha perguntas objetivando saber se o sistema de governo dos países conveniados incentivava sua população a estudar em alguma instituição e cursos específicos no Brasil. Eles relataram que não há um incentivo especifico, o estudante faz a prova de proficiência em língua portuguesa e em outras matérias e, caso ele obtenha êxito, o governo ajuda na seleção do país, curso e instituição de ensino, de acordo com os interesses dos estudantes.

Sobre o PROMISAES, os entrevistados relataram que ele é uma boa iniciativa porque dá oportunidades para as pessoas estudarem aqui no Brasil, assim como divulga o Brasil para outros países, aumentando o intercâmbio com os países envolvidos. O programa ajuda os estudantes a permanecerem nas instituições tranquilizando-os quanto às questões financeiras, porém os problemas de gestão e atrasos no pagamento das bolsas geram desconfortos e interferem no rendimento escolar.

\subsection{O que diz a teoria}

O Brasil, desde a década de 90, vem sendo alvo em potencial dos programas de ações afirmativas que visam superar as mazelas sociais, promover a inclusão, a justiça social e os direitos negados socialmente ao longo de sua história.

Ações afirmativas são medidas especiais e temporárias, tomadas pelo Estado e/ou pela iniciativa privada, espontânea ou compulsoriamente, com o objetivo de eliminar desigualdades historicamente acumuladas, garantindo a igualdade de oportunidade e tratamento, bem como compensar perdas provocadas pela discriminação e marginalização, por motivos raciais, étnicos, religiosos, de gênero e outros. (BRASIL, Ministério da Justiça, 1996).

Na visão de Nascimento (2010) “os programas de ações afirmativas são na verdade políticas de correção de desigualdades sociais e formas de efetivação de direitos. 
Portanto, defender as ações afirmativas é de fato se posicionar contra o mito da democracia racial e a exclusão social existente no Brasil."

As ações afirmativas objetivam promover o bem-estar e cidadania para garantir a igualdade de oportunidades e tratamento entre as pessoas, para assim haver a inclusão social. Porém, Junior (2004) analisa os prós e contras da adoção de políticas de ação afirmativa para a entrada de estudantes não brancos nas universidades. Ele identifica que ao se adotar essas políticas, ocorre uma segregação de um determinado grupo, o qual deveria ser beneficiado por elas, o que, de certa forma, caracteriza uma discriminação. Partindo dessa concepção, numa perspectiva realista, acrescenta que:

Para se produzir uma igualdade de fato, ou uma maior igualdade, muitas vezes é necessário fazer-se uma discriminação positiva. Seguro desemprego, leite para crianças pobres, bolsa-família, auxílio alimentação, tratamento especial para deficientes físicos, remédios para pessoas com AIDS, todas essas são medidas de discriminação positiva e só se justificam pelo argumento moral de se proporcionar às pessoas beneficiadas o mínimo de dignidade, do qual todos que vivem nessa sociedade devem igualmente usufruir. Se entendermos isso claramente, podemos ver que a ação afirmativa é só mais uma política do Estado de Bem-Estar Social. Ela se assenta sobre a constatação de que uma parcela da população tem suas chances de gozar dos benefícios da vida em sociedade em pé de igualdade com seus concidadãos [...], e que a proteção formal contra a discriminação dessa parcela, ou seja, as leis que coíbem a discriminação racial, baseadas no princípio universal da não-discriminação, não são eficazes. (JUNIOR, 2004, p. 297).

$\mathrm{O}$ autor ainda pontua resumidamente que:

1) quase metade da população brasileira (pretos e pardos) sofre de mecanismos sociais de exclusão que não são remediados pela igualdade formal do direito; 2) há comprovação de desigualdade pronunciada entre brancos e não-brancos em nossa sociedade, expressa em diferenciais de renda, educação e ocupação; 3) essa desigualdade tem resistido à passagem do tempo e ao processo de modernização do sistema produtivo e das instituições políticas e sociais do país; 4) os cargos e posições de maior prestígio em nossa sociedade são quase exclusivamente ocupados por pessoas brancas; por fim, 5) a educação parece ser um momento chave de produção ou de reprodução dessa desigualdade. Dado esse estado de coisas, políticas de ação afirmativa parecem plenamente justificáveis. (JUNIOR, 2004, p. 300).

Partindo do exposto, Junior (2004) menciona que o debate sobre ação afirmativa para o ingresso de não brancos no ensino está repleto de argumentos baseados em valores de uma sociedade particular, e discute se essa adoção é justa ou correta. Ele afirma que:

A implantação de políticas públicas, assim como outras modalidades de ação humana, sempre gera benefícios e consequências negativas inesperadas. A maneira de proceder frente a isso é reformular critérios e procedimentos com vistas a arrefecer os efeitos negativos e continuar a experimentação com vistas ao aprimoramento dos resultados da política pública. (JUNIOR, 2004, p. 307). 
Com isso, percebe-se a necessidade de criação de políticas afirmativas no país, uma vez que elas reconhecem a intensa exploração que os grupos afrodescendentes passaram, sendo considerados como um bem comerciável. Nesse período escravocrata, conforme afirma Heilbom, Araújo e Barreto (2010d), a raça era classificada e hierarquizada a partir de características psicológicas, biológicas, sociais e até de caráter, pelas quais se definiam os grupos, de modo que o indivíduo estava submetido às características (boas e/ou ruins) de sua raça. "O conceito de raça, tal como o empregamos hoje, nada tem de biológico. É um conceito carregado de ideologia, pois como todas as ideologias ele esconde uma coisa não proclamada: a relação de poder e de dominação.” (MUNANGA, 2003 apud HEILBOM; ARAÚJO; BARRETO, 2010c).

Definia-se assim, uma hierarquia na qual brancos e brancas de origem europeia eram entendidos como superiores (do ponto de vista moral, fisco e psicológico) em detrimento dos/as indígenas autóctones, asiáticos/as e negros/as africanos/as, ainda que pelo pensamento racial, houvesse subdivisões dentro dos grupos. Por fim, a mistura vislumbrada na miscigenação era entendida como degenerescente, ou seja, o produto do cruzamento inter-racial era visto como degenerado, fraco e incorporando as características negativas de cada grupo. (HEILBOM; ARAÚJO; BARRETO, 2010d, p. 3).

Diante das políticas de ação afirmativa existem correntes que as defendem fortemente de acordo com os argumentos já mencionados, mas também existem profundas críticas a elas. Uma dessas críticas sustenta a ideia de que essas políticas podem contribuir para o declínio da qualidade de ensino por violar o critério de mérito e de seleção (JUNIOR, 2004).

\begin{abstract}
Certamente, se tomarmos a política de cotas como exemplo de ação afirmativa, veremos que a nota de corte dos não-brancos será inferior à dos brancos. Isso não significa, contudo, que seu desempenho na universidade também o será. No caso das universidades americanas, como mostram a diferença das notas entre brancos e negros explicou somente $20 \%$ da diferença de seu desempenho escolar. Fato é que na política de cotas a seleção se dá, dentro de cada grupo, também pelo critério do mérito. Consequentemente, os não-brancos a ingressar na universidade serão aqueles com as melhores notas dentro de seu grupo. Cursos concorridos, como medicina, odontologia e arquitetura, continuarão a selecionar alunos com um alto potencial de rendimento escolar, mesmo depois da implantação das cotas. Além do mais, os estudantes cotistas podem, se corretamente incentivados, apresentar uma motivação para o desempenho escolar maior do que a média dos estudantes. (JUNIOR, 2004, p. 305).
\end{abstract}

O autor ainda propõe que deve ser reconhecido o importante papel da universidade em contribuir para o bem comum, pois a desigualdade social é a maior mazela da sociedade brasileira, e dessa forma: 
Temos que concluir que a universidade deve necessariamente e ativamente trabalhar para a diminuição dessa desigualdade e não funcionar como um sistema de premiação individual daqueles que já ocupam posição de status elevado em nossa sociedade. (JUNIOR, 2004, p. 305).

\subsection{A Superação da democracia racial para uma democracia social}

$\mathrm{Na}$ perspectiva de Ferreira (2008), um dos principais fatores que reforçou a manutenção da espoliação do/a negro/a foi o desenvolvimento do mito da democracia racial, como uma espécie de anteparo a uma afrocidadanização no Brasil. Para o autor, essa ideologia de democracia racial serve de base para a ideia de que, uma vez abolida a escravidão, os/as negros/as adquiriram cidadania imediata, com oportunidades iguais e amplas possibilidades de mobilidade social.

Um dos fundadores dessa ideia de democracia racial foi Gilberto Freyre, que em suas obras transmitiu uma visão positiva da mistura racial brasileira, elogiando a mestiçagem e a tolerância em relação a ela. O autor transformou a negatividade do mestiço em positividade, completando os contornos de uma identidade que estava sendo desenhada no Brasil na primeira metade do século XX.

Nesse período, o Brasil estava em processo de urbanização e industrialização, o que permitiu a formação de uma classe média e de um proletariado urbano. A Revolução de 30, as mudanças políticas, a mudança no papel do Estado que tentava consolidar um desenvolvimento social, enfim, esse quadro de profundas mudanças nas relações sociais fez com que as teorias racistas se tornassem obsoletas, surgindo assim outra interpretação da realidade social brasileira. Com isso, o conceito de raça foi superado pelo de cultura, e nessa transformação foram eliminadas as dificuldades colocadas a respeito da herança do mestiço. Ortiz (2006, p.41) destaca que "ela permite ainda um maior distanciamento entre o biológico e o social, o que possibilita uma análise mais rica da sociedade." O autor ainda expõe que:

O mito das três raças torna-se então plausível e pode-se tornar como ritual. A ideologia da mestiçagem, que estava aprisionada nas ambiguidades das teorias racistas, ao ser reelaborada pode difundir-se socialmente e se tornar senso comum, ritualmente celebrado nas relações do cotidiano, ou nos grandes eventos como o carnaval e o futebol. $\mathrm{O}$ que era mestiço torna-se nacional. (ORTIZ, 2006, p. 41).

Dessa forma, "a positivação da mistura de raças serviu como fator de união de um país gigante e heterogêneo, e também como instrumento de repressão às manifestações 'culturais' que se mostrassem alheias ao projeto" (JUNIOR, 2004, p. 8). Como 
consequência disso, o preconceito ${ }^{2}$ se tornou um tabu, pois o que se transmitiu foi que ele não poderia existir em um país cujo cerne de sua identidade é a dissolução do conceito de raça através da miscigenação.

Olhando esse quadro se poderia supor que os problemas raciais, finalmente, haviam se resolvido. Raça não condenava mais a nação, uma vez substituída pela categoria 'cultura'; a democracia racial afirmava a convivência pacífica e igualitária entre grupos raciais diferentes; manifestações e elementos culturais de origem negra/africana, antes repudiados, haviam sido elevados à categoria de expressão da nação brasileira, constituída por um povo mestiço. (HEILBOM; ARAÚJO; BARRETO, 2010b, p.2).

Ortiz (2006) também considera essa ideia como um mito que tem um ponto de origem, um centro a partir do qual se irradia a história mítica:

A ideologia do Brasil-cadinho relata a epopeia das três raças que se fundem nos laboratórios das selvas tropicais. Como nas sociedades primitivas, ela é um mito cosmológico, e conta a origem no moderno Estado brasileiro, ponto de partida de toda uma cosmologia que antecede a própria realidade. (ORTIZ, 2006, p. 38)

Já o conceito de democracia social, na visão de Dias (2006), enfatiza a preservação da igualdade política formal, sem deixar de lado a luta para transformar a desigualdade social existente nas instituições públicas e privadas. Ela trata de mecanismos participativos que viabilizam a igualdade social e a quebra dos autoritarismos institucionais. Para o autor, os processos de democratização social propõem uma flexibilização nos valores que sustentam as bases da autoridade reduzindo, portanto, as margens de desigualdade social.

Cunha (2007) descreve que promover a democracia social no Brasil com os descendentes africanos, além de considerar serem estes grupos os maiores construtores do que podemos identificar hoje como Brasil, também significa reconhecer as contribuições desse povo para o "conhecimento tecnológico universal"; as quais, durante muito tempo, foram mascaradas pelo eurocentrismo, ou seja, pela crença na superioridade dos povos europeus sobre os demais povos. Vários exemplos dessas contribuições estão nas mais diversas áreas do conhecimento como medicina, astronomia, engenharia, arquitetura, matemática e navegação.

Se considerarmos que a ciência e a tecnologia são campos do conhecimento utilizados, em essência, na compreensão e manejo do ambiente que nos cerca,

\footnotetext{
${ }^{2}$ De acordo com Helborn, Araújo e Barreto (2010b), o preconceito é utilizado pelo grupo que perde seus privilégios racialmente herdados, como uma tentativa de dar continuidade a uma ordem racial que não existe mais em termos jurídicos.
} 
podemos depreender que todos os povos, em seus mais remotos momentos históricos, foram dotados de conhecimento científico e tecnológico (apresentando entre si peculiaridades quanto a conceitos, objetivos e métodos empregados) para atender aos níveis de complexidade de suas sociedades. O desenvolvimento das nações nessas áreas do conhecimento deve-se, principalmente, às particularidades dos seus processos históricos e culturais. Isso não está relacionado com maior ou menor grau de inteligência ou aptidão de certos agrupamentos humanos. É interessante enfatizar essa questão para dissiparmos teorias racistas a respeito da suposta inferioridade de determinados grupos humanos em relação a outros no que se refere à capacidade cognitiva para empreender o desenvolvimento em suas sociedades. (CUNHA, 2007, p. 3)

\section{CONCLUSÃO}

No desenvolvimento deste trabalho, constatou-se que a adoção de políticas públicas no ensino superior envolve um conjunto de interesses e agentes sociais específicos que, por sua vez, se beneficiarão de sua implantação. Com isso, existem grupos não envolvidos com essas políticas que expõem os pontos negativos de sua efetivação; porém, não é bom para quem nunca sofreu discriminação adotar uma postura paralisada quanto às diferenças, pois as políticas de ação afirmativa são uma das ferramentas de luta contra a discriminação social e racial. Continuar adotando posturas conservadoras e elitistas significa fechar os olhos frente à gravidade do problema em questão.

Analisando o PROMISAES como política afirmativa, pode-se identificar que o programa é uma excelente proposta para a promoção da democracia social, uma vez que procura promover a diminuição das desigualdades sociais nos países conveniados, através de bolsas de estudo em instituições brasileiras, assim como recompensar o esforço histórico dispendido pelos ancestrais dos estudantes beneficiados, aqui no país, durante séculos. Em contraponto, é preciso destacar que o programa possui carências no que se refere à divulgação e conhecimento de sua proposta por parte dos beneficiados. No geral, a pesquisa identificou que o PROMISAES é uma interessante política de ação afirmativa, mas que necessita de alguns reajustes.

Por fim, consideram-se as políticas de ação afirmativa como tradução de uma efetiva ação política de cunho estatal que objetiva constituir um novo pacto social, com recorte étnico-racial, minimizando a enorme distância social que envolve negros e brancos.

Assim, as cotas seriam medidas focais para promover, em médio e longo prazo, melhor distribuição de renda, mas também para democratizar o acesso a 
espaços sociais e culturais antes impossíveis para negros - como a universidade pública, cargos de maior prestígio e bons salários. (FONSECA, 2009, p.111)

À luz da discussão proposta neste trabalho, é interessante citar Raichelis (2006), ao destacar que a formulação, a gestão e o financiamento das políticas sociais devem ser consideradas primazia do Estado; porém, essa primazia não implica exclusividade e, nesse sentido, democratizar a gestão das políticas sociais é um desafio a ser enfrentado pela sociedade civil.

\section{REFERÊNCIAS}

AZEVEDO, J. M. L. de. A educação como política pública. Campinas, S.P, vol. 56, 2004.

BRASIL. Estatuto da Igualdade Racial. Lei $\mathrm{n}^{\circ}$ 12.288, de 20 de julho de 2010. Altera as Leis $\mathrm{n}^{\circ} 7.716$ de 5 de janeiro de 1989, 9.029, de 13 de abril de 1995, 7.347, de julho de 1985 , e 10.778 , de 24 de novembro de 2003.

BRASIL. Portaria $n^{0}$ 3167, de 13 de setembro de 2005. Estabelece diretrizes para execução do Projeto Milton Santos de Acesso ao Ensino Superior (PROMISAES). Diário Oficial [da] República Federativa do Brasil. Brasília, DF, 15 set 2005. Disponível em <http://portal.mec.gov.br/sesu/arquivos/pdf/Promisaes/portaria3167.pdf $>$. Acesso em 02 agosto de 2010 .

BRASIL, Ministério da Educação e Cultura. PEC-G Programa de Estudantes Convênio de Graduação. Disponível em $<$ http://portal.mec.gov.br/pec-g $>$. Acesso em 04 de agosto de 2010.

CUNHA, L. Contribuição dos povos africanos para o conhecimento científico e tecnológico universal. Disponível em <http://www.acaoeducativa.org.br/fdh/wpcontent/uploads/2012/11/contribuicao-povos-africanos.pdf $>$. Acesso em 01 julho de 2010 .

DIAS. M. M. Org. Glossário de termos utilizados em desenvolvimento rural. Instituto Souza Cruz. Rio de Janeiro: Instituto Souza Cruz, 2006

FEREIRA, R. O mapa das ações afirmativas na educação superior. Trabalho apresentado no Foro Latinoamericano de Políticas Educativas- FLAPE, abril 2008.

FONSECA, D. J. A tripla perspectiva: a vinda, a permanência e a volta de estudantes angolanos no Brasil. Revista Pró-posições, Campinas, v. 20, n. 1 (58), p. 23-44, jan./abr. 2009.

HEILBOM, L. A; ARAÙJO, L.; BARRETO, A. Orgs. Gestão de Políticas Públicas em Gênero e Raça/ GPP - GER: módulo I, volume 3. Introdução ao racismo. Rio de Janeiro: CEPESC; Brasília: Secretaria Especial de Políticas para as Mulheres, 2010. 
HEILBOM, L. A; ARAÙJO, L.; BARRETO, A. Orgs. Gestão de Políticas Públicas em Gênero e Raça/ GPP - GER: módulo I, volume 3. Quando raça passou a ser um problema nacional: abolição, teorias racistas e o ideal de embranquecimento. Rio de Janeiro: CEPESC; Brasília: Secretaria Especial de Políticas para as Mulheres, 2010.

HEILBOM, L. A; ARAÙJO, L.; BARRETO, A. Orgs. Gestão de Políticas Públicas em Gênero e Raça/ GPP - GER: módulo I, volume 3. Anos decisivos 1940-1960: a possibilidade da democracia racial. Rio de Janeiro: CEPESC; Brasília: Secretaria Especial de Políticas para as Mulheres, 2010.

HEILBOM, L. A; ARAÙJO, L.; BARRETO, A. Orgs. Gestão de Políticas Públicas em Gênero e Raça/ GPP - GER: módulo I, volume 3. Estruturação do campo de desigualdades no Brasil e o debate entre sociólogos/as e antropólogos/as. Rio de Janeiro: CEPESC; Brasília: Secretaria Especial de Políticas para as Mulheres, 2010.

JUNIOR, J. F. Ação afirmativa no Brasil: fundamentos e críticas. Revista Econômica, Rio de Janeiro, v.6, n.2, p.291-312, dez. 2004.

NASCIMENTO, J do. (2010). Ações afirmativas e políticas públicas de inclusão social. Disponível em <https://www.meuartigo.brasilescola.com/sociologia/acoesafirmativas-politicas-publicas-inclusao-social.htm $>$. Acesso em 2 agosto de 2010.

ORTIZ, Renato. Cultura brasileira e identidade nacional. São Paulo: Brasiliense, 2006.

RAICHELIS, R. Democratizar a Gestão das Políticas Sociais - um desafio a ser enfrentado pela Sociedade Civil. In: MOTA, M.E. (et al) Serviço Social e Saúde: formação e trabalho profissional. São Paulo: OPAS, OMS, Cortez, 2006. p. 73-87 